\title{
Converter for the Drive of two Brushed DC motors
}

\author{
FELIX A. HIMMELSTOSS \& HELMUT L. VOTZI \\ Power Electronics Department \\ University of Applied Sciences Technikum Wien \\ Hoechstaedtplatz 6, A-1200 Wien \\ AUSTRIA
}

\begin{abstract}
Brushed DC-motors are, due to their simplicity and easiness to control, still more and more used. Here a converter for two machines is treated. The basic two-quadrant converter for supplying two machines is described, the converter is designed. The expansion to a four-quadrant drive and the reduction to a onequadrant drive for both motors are explained. The mathematical model for the drives are derived, and the transfer functions are calculated with the help of the signal flow graph. Simulations close and prove the investigations.
\end{abstract}

Key-Words: - brushed DC machine, PMDC motor, double converter, DC/DC converter, three-port converter, recuperation, signal flow graph, small signal model, transfer function, simulation

Received: June 3, 2020. Revised: October 10, 2020. Accepted: November 5, 2020. Published: November 21, 2020.

\section{Introduction}

DC motor drives are currently still important. The brushed DC motor market is expected to witness a market growth at an annual rate of $6.50 \%$ in the forecast period of 2020 to 2027 [1]. Brushed DC machines of small power are used e.g. for auxiliary drives in automotive applications, in model planes and cars, and because of the low weight also in drones. In the large power range, they are interesting in retrofit applications e.g. in trams our trolley busses. The here described converter (Fig. 1) can be built for small power applications as well as for large drives. This topology needs only three bidirectional switches to control two DC machines in two-quadrants. In the four-quadrant version (Fig. 8), only six bidirectional switches are needed and when only one-quadrant operation is necessary, only two bidirectional switches and one diode are necessary (Fig. 9). The starting point for this investigation was [2], which describes possible topologies for three-port converters. Other DC/DC converter topologies which could be used for the driving of DC-motors can be found in the textbooks [3 - 5]. Numerous other DC/DC converters can be found in the literature e.g. [6-11]. Interesting applications for DC motor drives for ship and kart propulsion, for starters, pumps and wind turbines are given e.g. in [12 - 19]. Some considerations for the control can be found in [20 - 21].

The here described converter is especially useful when two motors should be controlled simultaneously. It has a reduced number of semiconductors compared to all other concepts. At first the two quadrant drive is analyzed by inspection and the important signals are drawn for better understanding. Then the converter is designed and the model is derived. The transfer functions are calculated from a signal flow graph, which describes the drive. Some simulations are shown and the extension to the four- and the reduction to the onequadrant converters are also explained.

\section{Double Machine Drive Basics}

The double machine drive consists in its basic topology (Fig. 1) of a series connection of three current bidirectional switches. Each switch is built by an active switch with an antiparallel diode. The active switches can be MOSFETs for low voltages and IGBTs for higher voltages and power.

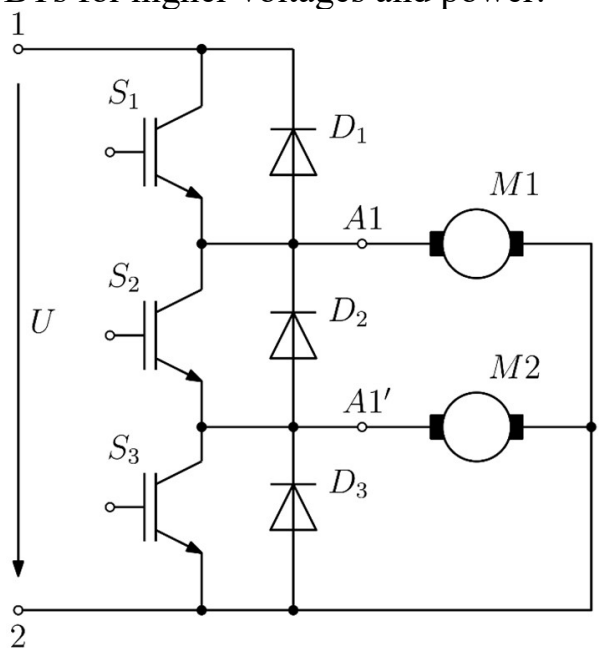

Fig. 1. Two-quadrant double motor drive

\subsection{Ideal converter signals}

The drive system will now be analyzed and explained with the help of time diagrams of the voltages across and the currents through the devices 
in the ideal case. That means no resistors, and infinite switching speed is provided. For the figures it is assumed that the duty cycle (the on-time in dependence of the switching period $\mathrm{T}$ ) of switch $\mathrm{S}_{1}$ is two third and that of $S_{2}$ is one third. The control signals are depicted in Fig. 2. The machines are modelled by the armature resistor $\mathrm{R}_{\mathrm{M}}$, the armature inductor $\mathrm{L}_{\mathrm{M}}$ and the voltage constant $\mathrm{C}_{\mathrm{E}}$. The number in the index $(1,2)$ marks the machine. For the ideal investigations the armature resistor however is set to zero.

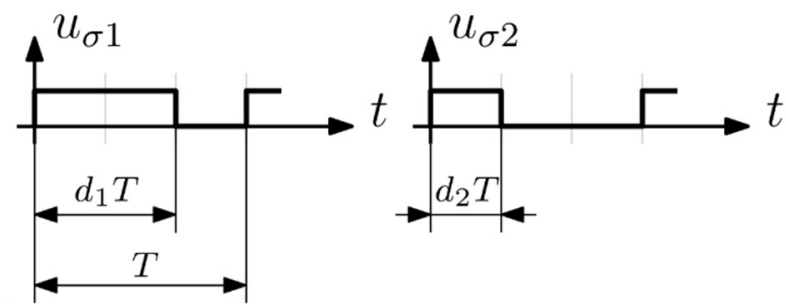

Fig. 2. Control signals

During the on-time of the active switches the voltage across the armature inductor $\mathrm{L}_{\mathrm{M}}$ is the difference between the input voltage and the source voltage of the machine. This is valid for both machines. When active switch $\mathrm{S}_{2}$ turns off, the diode $\mathrm{D}_{3}$ turns on and the voltage across $\mathrm{L}_{\mathrm{M} 2}$ is now the negative source voltage of the machine M2. Machine M2 is now in the free-wheeling stage. When switch $S_{1}$ is turned off, the negative source voltage is applied to $\mathrm{L}_{\mathrm{M} 1}$ and machine $\mathrm{M} 1$ is now also in the freewheeling stage. The voltages across the motor inductors are shown in Fig. 3. It is assumed that the source voltage of machine M2 is lower than that of machine M1.

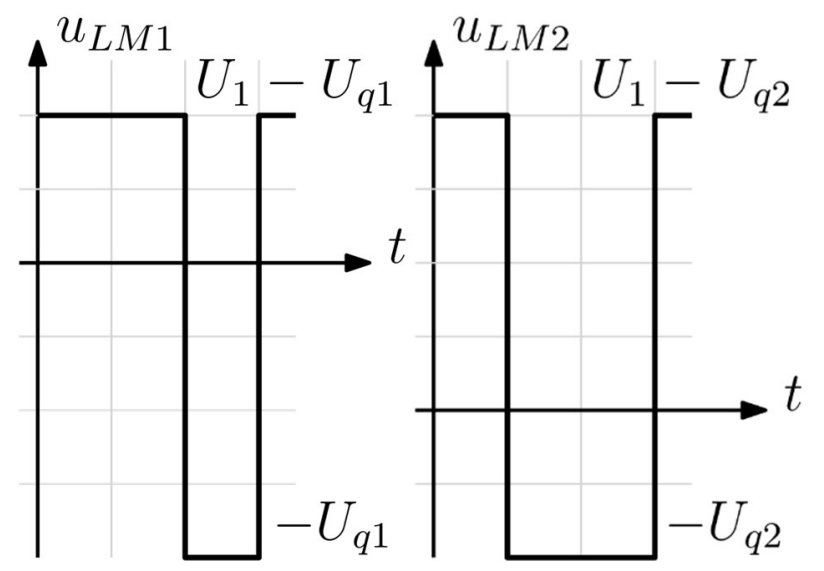

Fig. 3. Voltages across the armature inductors

When the voltage is positive across the armature inductors, the current is increasing and when the voltage across the inductor is negative, the current is decreasing. The inductor values of the machines are large. Therefore, the current changes only a little within a switching period.

With the help of the voltage-time balance (in the steady state the voltage across an inductor has to be zero in the mean) one can calculate the yielded source voltages of the machines

$$
\left(U_{1}-U_{q i}\right) d_{i}=\left|-U_{q i}\right|\left(1-d_{i}\right) \text {. }
$$

The source voltage of the idealized machines can therefore be written according to

$$
\begin{aligned}
& U_{q 1}=U_{1} d_{1} \\
& U_{q 2}=U_{1} d_{2} .
\end{aligned}
$$

The voltage is proportional to the speed and the speed is nearly constant during one switching period due to the momentum of inertia. With the voltage constant $\mathrm{C}_{\mathrm{E}}$ the speed can be given to

$$
\begin{aligned}
& n_{1}=\frac{1}{C_{E 1}} U_{1} d_{1} \\
& n_{2}=\frac{1}{C_{E 2}} U_{1} d_{2} .
\end{aligned}
$$

The voltage across the semiconductor switches is zero when the switches are turned on (during $\mathrm{d}_{1} \mathrm{~T}$ for $S_{1}$ and $d_{2} T$ for switch $S_{2}$ ) and equal to the input voltage when the switches are turned off. The voltage across $\mathrm{S}_{3}$ is equal to the input voltage and is zero when switch $\mathrm{S}_{2}$ is turned off. The voltage across the active switches $S_{1}$ and $S_{2}$ can be seen in Fig. 4 and across $S_{3}$ in Fig. 7.

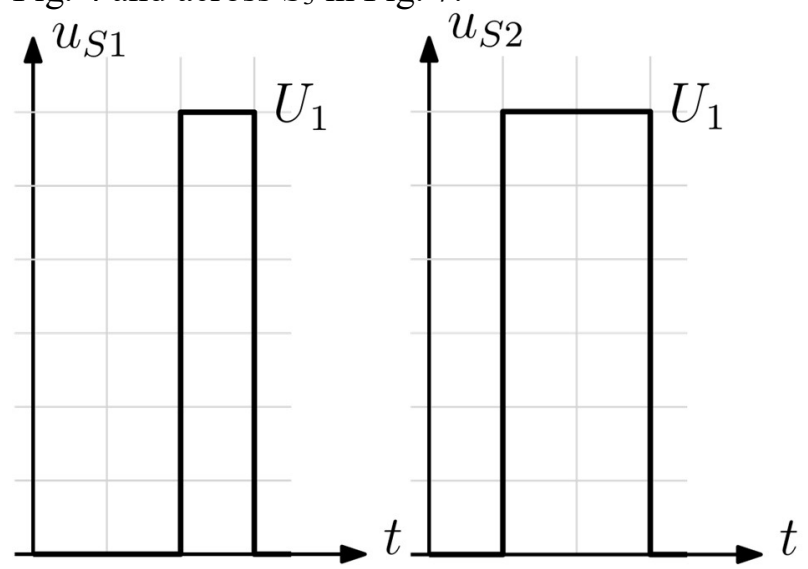

Fig. 4. Voltages across the active switches $S_{1}$ and $S_{2}$

The current through the machines is caused by the load torque. The machine produces a torque which is proportional to the armature current. The proportional factor is the torque coefficient $\mathrm{C}_{\mathrm{T}}$.

In the steady state the load torque and the torque which is produced by the machine are the same. The currents in the machines are nearly constant. This is because the time constant of the armature winding is large compared to the switching period. 
The current is assumed for the two machines in Fig. 5.

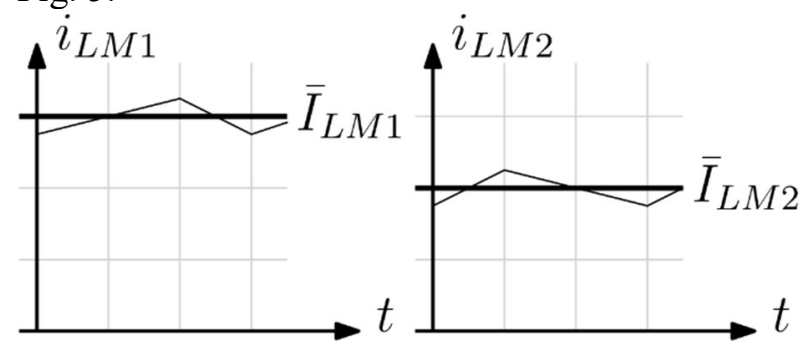

Fig. 5. Currents through the machines

For better understanding a small ripple is shown. At large loads, the inductor is smaller because of saturation effects of the iron. The currents through the switches $S_{1}$ and $S_{2}$ are shown in Fig. 6 and through $\mathrm{S}_{3}$ in Fig. 7.

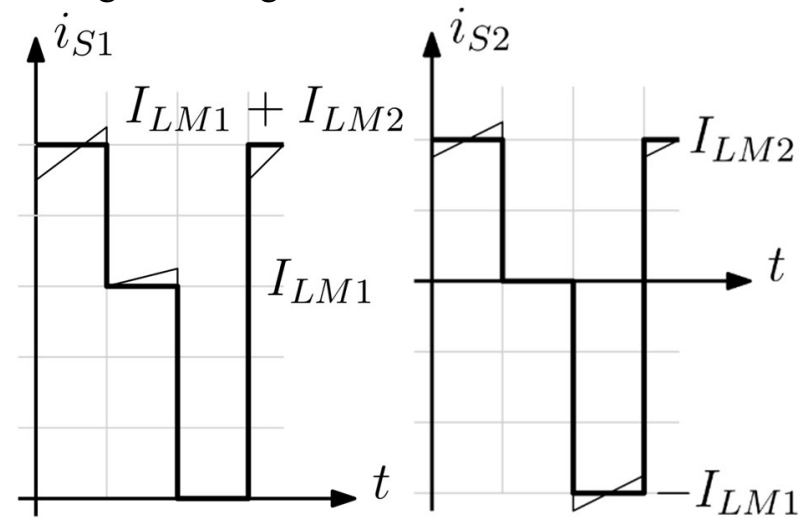

Fig. 6. Current through the switches $S_{1}$ and $S_{2}$

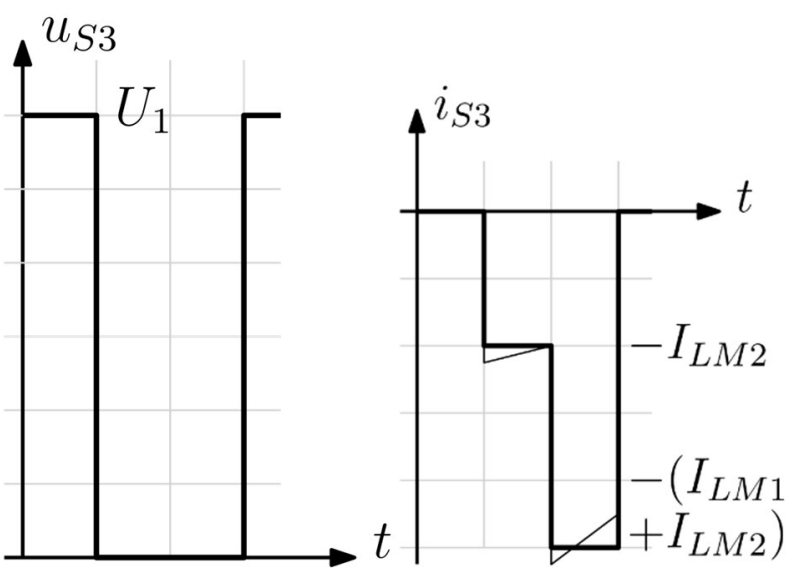

Fig.7. Voltage across and current through $\mathrm{S}_{3}$

The converter was described in detail for the driving mode (motor operation). In Table I the conducting semiconductors are marked with a cross $\mathrm{x}$. In the first column $\mathrm{T}$ means motoring, $\mathrm{F}$ stands for freewheeling, and $\mathrm{R}$ signifies recuperation (feeding back the brake energy). M1 and M2 stands for the appropriate machines. It should be mentioned that it is also possible to drive only one machine alone (e.g. M1 or M2). Both machines can also be controlled by the same duty cycle $\left(S_{1}\right.$ and $S_{2}$ are turned on and off synchronously).

Table I: Modes of the two-quadrant drive

\begin{tabular}{|c|c|c|c|c|c|c|}
\hline Mode & S1 & D1 & S2 & D2 & S3 & D3 \\
\hline TM1 & $x$ & & & & & \\
\hline TM2 & $x$ & & $x$ & & & \\
\hline TM1 & $x$ & & & & & \\
\hline FM2 & & & & & & $x$ \\
\hline FM1 & & & & $x$ & & $x$ \\
\hline FM2 & & & & & & $x$ \\
\hline RM1 & & $x$ & & & & \\
\hline FM2 & & & & & & $x$ \\
\hline RM1 & & $x$ & & & & \\
\hline RM2 & & & & $x$ & & \\
\hline
\end{tabular}

\section{Design of the converter}

From these considerations in section 2 the necessary blocking voltage of the switches is evident. The blocking voltage for all semiconductor switches must be higher than the input voltage. We would recommend a factor of 1.6 to 2 higher blocking voltage than the input voltage. The onward-losses can be calculated from the current shapes shown in the Figs. 6 and 7. The RMS values of the currents can be calculated easily because the current through the machines can be assumed as nearly constant. With the definition

$$
I_{R M S}=\sqrt{\frac{1}{T} \int_{0}^{T} i^{2} d t}
$$

one gets for the MOSFETs

$$
\begin{gathered}
I_{R M S, S 1}^{2}=\left(I_{L M 1}+I_{L M 2}\right)^{2} d_{2}+I_{L M 1}^{2}\left(d_{1}-d_{2}\right) \\
I_{R M S, S 2}^{2}=I_{L M 2}^{2} d_{2}+I_{L M 1}^{2}\left(1-d_{1}\right) \\
I_{R M S, S 3}^{2}=I_{L M 2}^{2}\left(d_{1}-d_{2}\right)+\left(I_{L M 1}+I_{L M 2}\right)^{2}\left(1-d_{1}\right) .
\end{gathered}
$$

When MOSFETs are used and synchronous rectification is applied (in case the body diodes would conduct they are shunted by the antiparallel switch), the losses can directly be calculated by multiplying the squares of the RMS-value with the appropriate $\mathrm{R}_{\mathrm{DS}}$ of the switch

$$
P_{S i}=I_{R M S, S i}^{2} R_{D S, i} \text {. }
$$

The losses for an IGBT (modelled by a constant forward Voltage $\mathrm{V}_{\mathrm{F}}$ and a differential resistor $\mathrm{R}_{\mathrm{CE}}$ ) can be calculated by

$$
P_{I G B T i}=V_{F} \bar{I}_{S i}+I_{R M S, S i}^{2} R_{C E, i}
$$

where $\bar{I}_{S i}$ is the mean value of the switch current. The mean value for $S_{1}$ can be calculated according to

$$
\bar{I}_{S 1}=\left(I_{L M 1}+I_{L M 2}\right) d_{2}+I_{L M 1}\left(d_{1}-d_{2}\right) .
$$


Considering $\mathrm{S}_{2}$ one can see that only during $\mathrm{d}_{2} \mathrm{~T}$ current of machine M2 is flowing through the IGBT and during the time interval $\left(1-\mathrm{d}_{1}\right) \mathrm{T}$ the current through M1 is flowing through the antiparallel diode $D_{2}$. The RMS-value and the mean values for $S_{2}$ and $\mathrm{D}_{2}$ are therefore

$$
\begin{aligned}
& I_{R M S, S 2}^{2}=I_{L M 2}^{2} d_{2} \\
& I_{R M S, D 2}^{2}=I_{L M 1}^{2}\left(1-d_{1}\right) \\
& \bar{I}_{S 2}=I_{L M 2} d_{2} \\
& \bar{I}_{D 2}=I_{L M 1}\left(1-d_{1}\right) .
\end{aligned}
$$

In the motoring mode $S_{3}$ is not turned on, only the diode $\mathrm{D}_{3}$ is conducting. The active switch $\mathrm{S}_{3}$ is only necessary when the machines have to brake. The RMS- and the mean-value for $\mathrm{D}_{3}$ can be given by

$$
\begin{aligned}
I_{R M S, D 3}^{2} & =I_{L M 2}^{2}\left(d_{1}-d_{2}\right)+\left(I_{L M 1}+I_{L M 2}\right)^{2}\left(1-d_{1}\right) \\
\bar{I}_{D 3} & =I_{L M 2}\left(d_{1}-d_{2}\right)+\left(I_{L M 1}+I_{L M 2}\right)\left(1-d_{1}\right) .
\end{aligned}
$$

Now one is able to calculate the onward losses of the semiconductors, when IGBTs and diodes are used (or when the losses of the channel of the MOSFETs are higher than that of the antiparallel diode)

$$
\begin{aligned}
& P_{I G B T 1}=V_{F} \bar{I}_{S 1}+I_{R M S, S 1}^{2} R_{C E, 1} \\
& P_{I G B T 2}=V_{F} \bar{I}_{S 2}+I_{R M S, S 2}^{2} R_{C E, 2} \\
& P_{D 2}=V_{D 2} \bar{I}_{D 2}+I_{R M S, D 2}^{2} R_{D, 2} \\
& P_{D 3}=V_{D 3} \bar{I}_{D 3}+I_{R M S, D 3}^{2} R_{D, 3} .
\end{aligned}
$$

The sum of these losses is the onward loss of the converter in the driving mode. The calculation must be done for the maximum motor currents. The switching losses can be reduced by using fast semiconductors (e.g. high bandwidth semiconductors). To reduce the derivative of the voltage across the machines, small LC filters (an inductor in series to the machine and a capacitor in parallel to the connectors of the machine) can be used.

For large drives only a small active switch is necessary, which only has to withstand the short braking phases. The loss calculation has to be done always for the worst-case.

\section{Expansions of the converter concept}

The described two-quadrant converter can be expanded to a four quadrant converter. Fig. 8 is drawn with MOSFETs. When the devices have fast body diodes, the diodes are automatically included in the power devices. With this converter driving and braking in both directions are possible. The braking energy can be fed into the power source.
This is especially useful for autonomic vehicles or traction systems.

As for the two-quadrant drive in Tab. I, tables are given in the appendix which show the conducting semiconductor devices. Tab. A.I is for the machines which are running to the right and Tab. A.II for running to the left. A cross $\mathrm{x}$ marks the conducting element, $\mathrm{T}$ stands for motoring, $\mathrm{F}$ for free-wheeling, and $\mathrm{R}$ for recuperation.

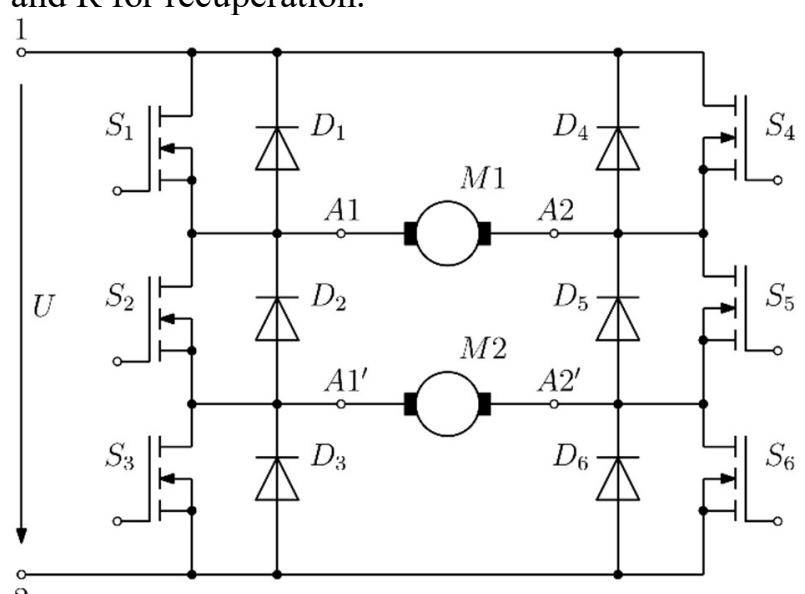

Fig. 8. Four-quadrant double motor drive

When only one drive direction is necessary, the twoquadrant double converter can be simplified. The active switch $\mathrm{S}_{3}$ is not necessary in this case. This is depicted in Fig. 9. This converter can be used for pumps, blowers etc.

It should be noticed that the direction of the speed is dependent on how the armature terminals are joined to the connectors of the converter. Therefore, it is also possible to have different directions of the speed for both motors.

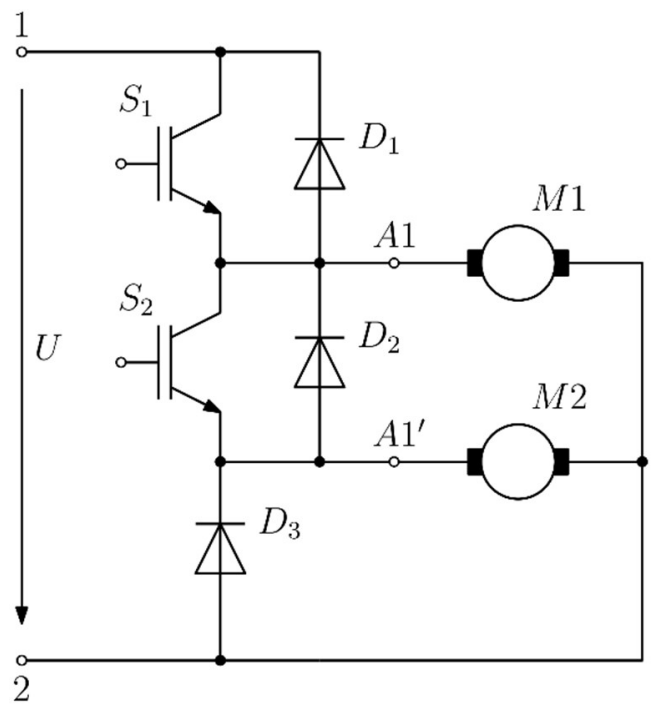

Fig. 9. One-quadrant double motor drive 


\section{Model of the drive}

The drive can be split into two independent parts (provided that the duty cycle $d_{2}$ is smaller than $d_{1}$, each machine can under this assumption be controlled independently). All variables written with small letters are functions of time.

There are three modes (Fig. 10). In the first mode both switches $S_{1}$ and $S_{2}$ are conducting (Fig.10.a). When $S_{2}$ is turned off, the converter goes into the second mode (Fig.10.b) where $\mathrm{S}_{1}$ and $\mathrm{D}_{3}$ are conducting. When $\mathrm{S}_{1}$ is turned off, $\mathrm{D}_{2}$ turns on (Fig.10.c).

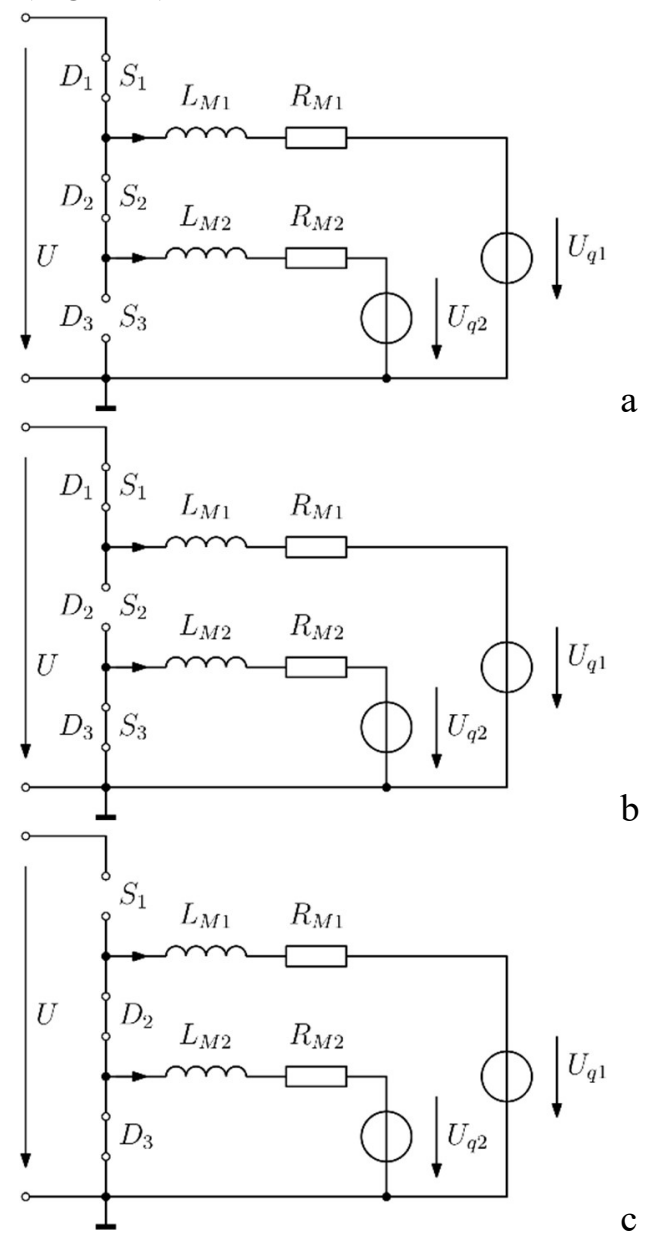

Fig. 10. Modes of the converter

For machine M1 one gets

$$
\begin{aligned}
& \frac{d i_{L M 1}}{d t}=\frac{-R_{M 1} i_{L M 1}-C_{E 1} n_{1}+d_{1} u_{1}}{L_{M 1}} \\
& \frac{d n_{1}}{d t}=\frac{C_{M 1} i_{M 1}-m_{L o a d M 1}}{2 \pi J_{M 1}} .
\end{aligned}
$$

To linearize the differential equations, the perturbation method is used. The variables are written as the value at the working point in steady state (written as capital letters with the index 0) added by a small disturbance value (written with small letters marked by a roof on top)

$$
\begin{aligned}
& i_{L M 1}=I_{L M 10}+\hat{i}_{L M 1} \\
& n_{1}=N_{10}+\hat{n}_{1} \\
& u_{1}=U_{10}+\hat{u}_{1} \\
& d_{1}=D_{10}+\hat{d}_{1} \\
& m_{L 1}=M_{L 10}+\hat{m}_{L 1} .
\end{aligned}
$$

In general, one can write for the two drives (index $\mathrm{i}$ symbolizes the drive number) for the small signal model

$$
\begin{aligned}
& \frac{d \hat{i}_{L M i}}{d t}=\frac{-R_{M i} \hat{i}_{L M i}-C_{E i} \hat{n}_{i}+D_{0 i} \hat{u}_{1}+U_{10} \hat{d}_{i}}{L_{M i}} \\
& \frac{d \hat{n}_{i}}{d t}=\frac{C_{M i} \hat{i}_{M i}-\hat{m}_{L o a d M i}}{2 \pi J_{M i}}
\end{aligned}
$$

Combined in matrix form one gets

$$
\frac{d}{d t}\left(\begin{array}{c}
\hat{i}_{L M i} \\
\hat{n}_{i}
\end{array}\right)=\left[\begin{array}{cc}
A_{11, i} & A_{12, i} \\
A_{21, i} & 0
\end{array}\right]\left(\begin{array}{c}
\hat{i}_{L M i} \\
\hat{n}_{i}
\end{array}\right)+\left[\begin{array}{ccc}
B_{11, i} & 0 & B_{13, i} \\
0 & B_{22, i} & 0
\end{array}\right]\left(\begin{array}{c}
\hat{u}_{1} \\
\hat{m}_{L i} \\
\hat{d}_{i}
\end{array}\right)
$$

To obtain the transfer functions, one must Laplace transform this matrix equation and calculate the transfer functions. Another method is to draw the signal flow graph directly from (28). The necessary integration is done by edges weighted by $1 / \mathrm{s}$. The signal flow graph is shown in Fig. 11.

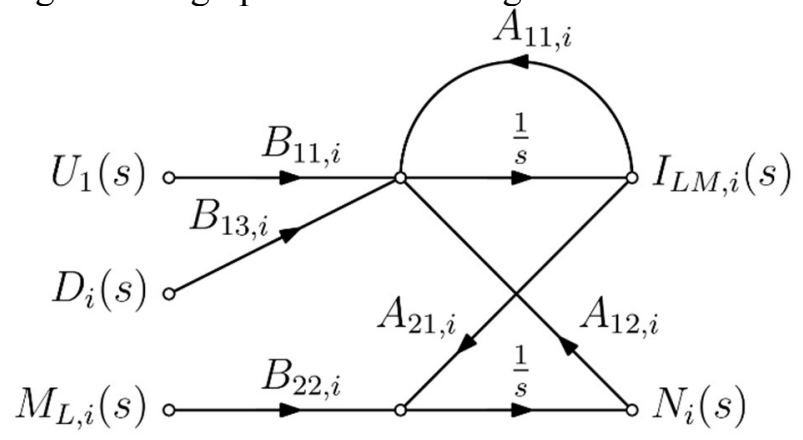

Fig. 11. Signal flow graph

At first we determine the transfer function between the speed and the duty cycle. The forward path can be written according to

$$
F_{i}: \frac{A_{21, i} B_{13, i}}{s^{2}} .
$$

There are two loops

$$
\begin{aligned}
& L_{1, i}: \frac{A_{11, i}}{s} \\
& L_{2, i}: \frac{A_{12, i} A_{21, i}}{s^{2}} .
\end{aligned}
$$

With Mason's equation one can write 


$$
\begin{aligned}
& \frac{N_{i}(s)}{D_{i}(s)}=\frac{F_{i}}{1-\left(L_{1, i}+L_{2, i}\right)} \\
& \frac{N_{i}(s)}{D_{i}(s)}=\frac{C_{M i}}{2 \pi J_{i}} \frac{U_{10}}{L_{M i}} \frac{1}{s^{2}+\frac{R_{M i}}{L_{M i}} s+\frac{C_{E i}}{L_{M i}} \frac{C_{M i}}{2 \pi J_{i}}} .
\end{aligned}
$$

To calculate the influence of the load torque on the speed one gets for the forward path

$$
F_{i}: \frac{B_{22, i}}{s} \text {. }
$$

The loops are the same, but we have one nontouching loop for the forward path $\left(\mathrm{L}_{1}\right)$. Therefore, one can write for the transfer function between speed and load torque

$$
\begin{aligned}
& \frac{N_{i}(s)}{M_{L i}(s)}=\frac{V_{i}\left(1-L_{1, i}\right)}{1-\left(L_{1, i}+L_{2, i}\right)} \\
& \frac{N_{i}(s)}{M_{L i}(s)}=-\frac{1}{2 \pi J_{i}} \frac{s+\frac{R_{M i}}{L_{M i}}}{s^{2}+\frac{R_{M i}}{L_{M i}} s+\frac{C_{E i}}{L_{M i}} \frac{C_{M i}}{2 \pi J}} .
\end{aligned}
$$

For the influence of the supply on the speed one gets for the forward path

$$
F_{i}: \frac{A_{21, i} B_{11, i}}{s^{2}} .
$$

The loops are the same and both loops touch the forward-path. One gets therefore for the transfer function between the speed and the input voltage

$$
\begin{aligned}
& \frac{N_{i}(s)}{U_{1}(s)}=\frac{F_{i}}{1-\left(L_{1, i}+L_{2, i}\right)} \\
& \frac{N_{i}(s)}{U_{1}(s)}=\frac{C_{M i}}{2 \pi J_{i}} \frac{D_{0 i}}{L_{M i}} \frac{1}{s^{2}+\frac{R_{M i}}{L_{M i}} s+\frac{C_{E i}}{L_{M i}} \frac{C_{M i}}{2 \pi J_{i}}} .
\end{aligned}
$$

If a speed control with an underlying current control is used, the transfer function between the current through the machines in accordance with the supply voltage and with the appropriate duty cycle and load torque have to be calculated.

For the transfer function between the current and the duty cycle one gets the forward path

$$
F_{i}: \frac{B_{13, i}}{s}
$$

which leads to

$$
\frac{I_{L M i}(s)}{D_{i}(s)}=\frac{U_{10}}{L_{M i}} \frac{s}{s^{2}+\frac{R_{M i}}{L_{M i}} s+\frac{C_{E i}}{L_{M i}} \frac{C_{M i}}{2 \pi J_{i}}} .
$$

With

$$
F_{i}: \frac{A_{12, i} B_{22, i}}{s^{2}}
$$

one gets

$$
\frac{I_{L M i}(s)}{M_{L i}(s)}=\frac{1}{2 \pi J i} \frac{C_{E 1}}{L_{M i}} \frac{1}{s^{2}+\frac{R_{M i}}{L_{M i}} s+\frac{C_{E i}}{L_{M i}} \frac{C_{M i}}{2 \pi J_{i}}}
$$

and with

$$
F_{i}: \frac{B_{11, i}}{s}
$$

the influence of the input voltage to the current through the machine is described by

$$
\frac{I_{L M i}(s)}{U_{1}(s)}=\frac{D_{i 0}}{L_{M i}} \frac{s}{s^{2}+\frac{R_{M i}}{L_{M i}} s+\frac{C_{E i}}{L_{M i}} \frac{C_{M i}}{2 \pi J_{i}}} .
$$

The steady state connections can be found directly from (28) and lead to

$$
\begin{aligned}
& -R_{M i} I_{L M i 0}-C_{E i} N_{i 0}+D_{i 0} U_{10}=0 \\
& C_{M i} I_{L M i}-M_{L M i 0}=0 .
\end{aligned}
$$

Or better

$$
\begin{aligned}
& N_{i 0}=\frac{D_{i 0} U_{10}-R_{M i} I_{L M i 0}}{C_{E i}} \\
& C_{M i} I_{L M i}=M_{L M i 0} .
\end{aligned}
$$

\section{Simulations}

The simulation was done for a motor which is used in a kart. It should be noted that the developed theory is also valid for machines with higher dynamics. The data of the machine are:

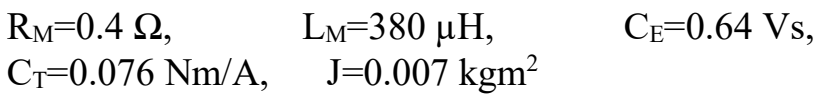

The chosen working point values are:

$\mathrm{U}_{10}=24 \mathrm{~V}, \quad \mathrm{I}_{\mathrm{M} 10}=10 \mathrm{~A}, \quad \mathrm{D}_{10}=0.1, \quad \mathrm{U}_{\mathrm{q} 10}=48 \mathrm{~V}$, $\mathrm{N}_{0}=31 \mathrm{rps}$

\subsection{Bode plots}

We show some Bode plots of the drive. Fig. 12 shows the speed with regard to the duty cycle and Fig. 13 the connection between momentum of the load and the speed. The low pass behavior can be seen clearly. In Fig. 14 the influence of the input voltage on the speed can be seen. In this case the gain for low frequencies is one.

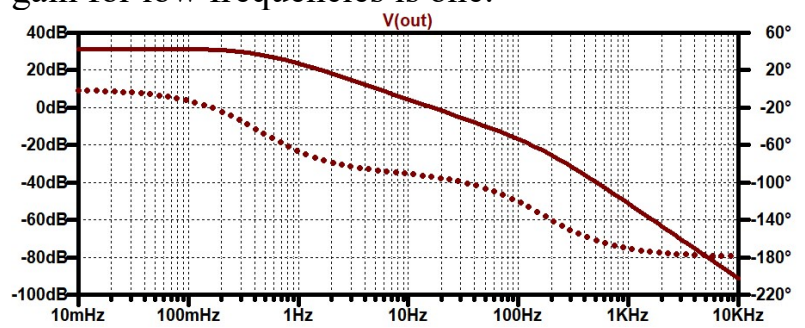

Fig. 12. Bode plot speed in relation to the duty cycle, c.f. (33) 


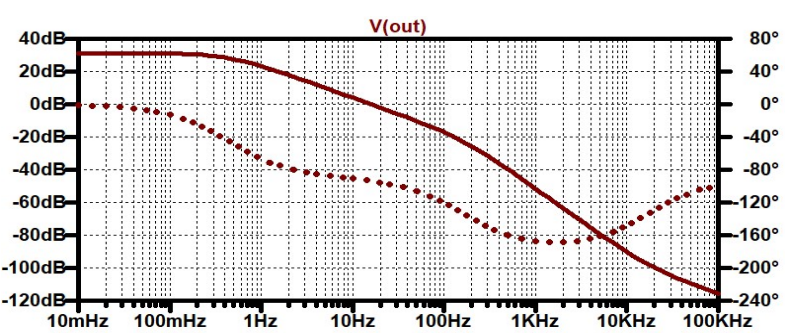

Fig. 13. Bode plot speed in relation to the momentum of load, c.f. (36)

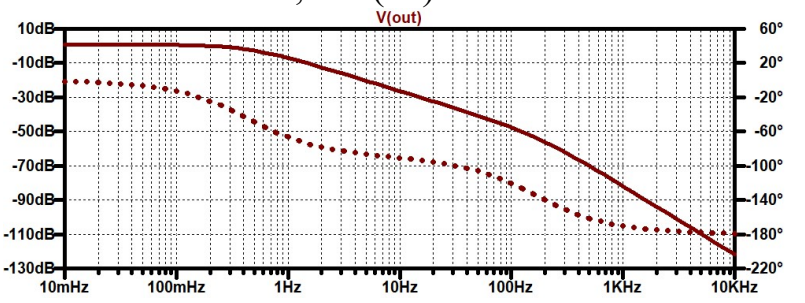

Fig. 14. Bode plot speed in relation to the input voltage, c.f. (39)

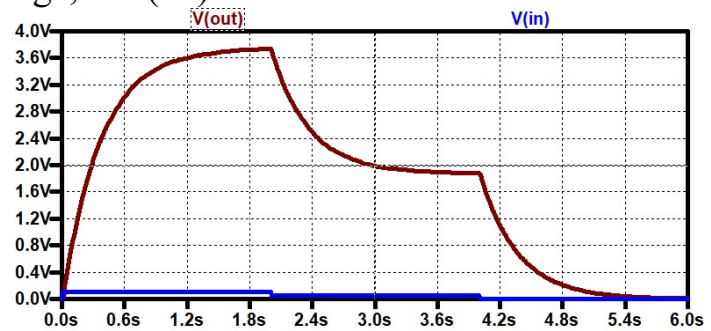

Fig.15. Step response to duty cycle (blue) steps, calculated by the transfer function (33)

The Bode plots between the armature current and the input variables show low-pass behavior for the load torque and band-pass characteristics for the influence of the duty cycle and the input voltage.

\subsection{Circuit oriented simulation}

Fig. 16 shows the current through the switches in steady-state. The similarity with the constructed graphs shown in Figs. $6 \& 7$ is obvious.

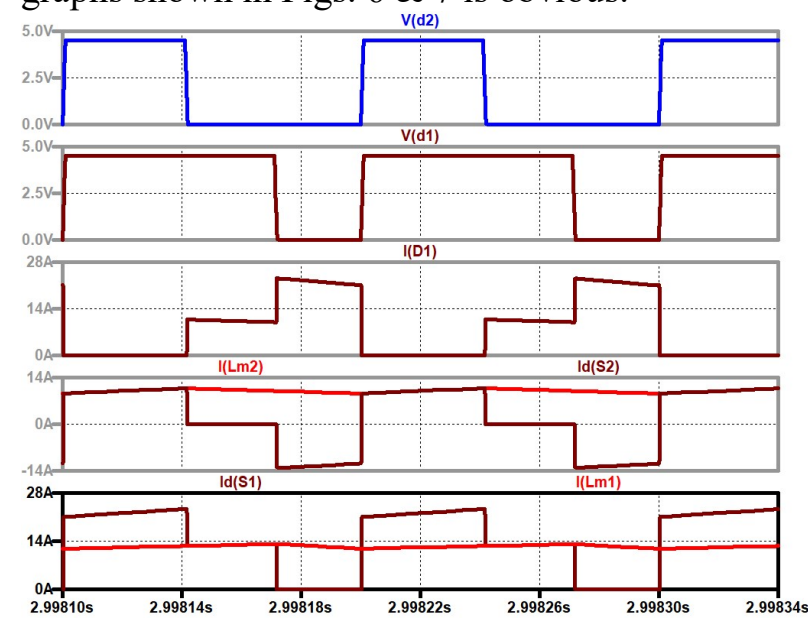

Fig. 16. Up to down: control signal for $\mathrm{S}_{2}$, control signal for $S_{1}$, current through $D_{3}$, current through $S_{2}$ and M2, current through $S_{1}$ and M1

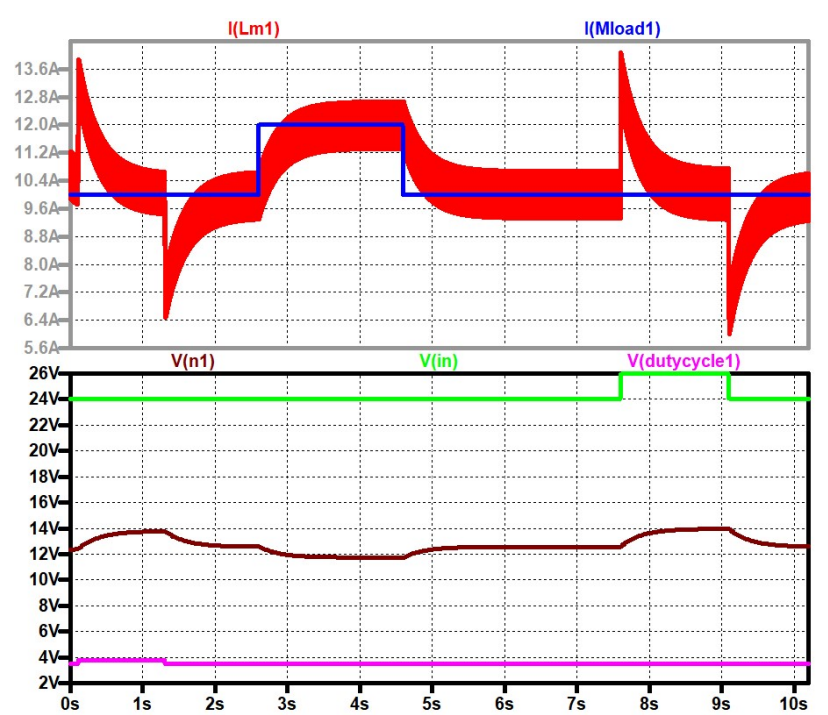

Fig. 17. Step response caused by duty cycle steps, load steps and input voltage steps shown for M1

Fig. 17 shows up to down the current through the machine M1 (red), the load torque (blue, represented in the simulation by an appropriate current), the input voltage (green), the source voltage (dark brown) and the control signal for the duty cycle (violet). The switching frequency is $10 \mathrm{kHz}$. A step response calculated with (33) is depicted in Fig. 15.

\section{Conclusion}

A family of converters for the control of two brushed DC motors was presented. Under the assumption that the duty cycle for $S_{1}$ is higher than or equal to that of $\mathrm{S}_{2}$, both machines can be controlled independently. Only a reduced number of semiconductor switches is necessary compared to the traditional control of two machines. The presented concept is useful for small power rates, but also for high power applications, especially current controlled, in the retrofit of trams and railway motor cars.

\section{References:}

[1] https://www.databridgemarketresearch.com/reports/global -brushed-dc-motor-market (visited Dec 21, 2020).

[2] G. Chen, Z. Jin, Y. Liu, Y. Hu, J. Zhang and X. Qing, Programmable Topology Derivation and Analysis of Integrated Three-Port DC-DC Converters with Reduced Switches for Low-Cost Applications, IEEE Transactions on Industrial Electronics, vol. 66, no. 9, pp. 6649-6660, Sept. 2019.

[3] N. Mohan, T. Undeland and W. Robbins, Power Electronics, Converters, Applications and Design, 3nd ed. New York: W. P. John Wiley \& Sons, 2003.

[4] F. Zach, Power Electronics, in German: Leistungselektronik, Wien: Springer, 5th ed., 2016.

[5] Y. Rozanov, S. Ryvkin, E. Chaplygin, P. Voronin, Power Electronics Basics, CRC Press, 2016. 
[6] S. Cuk, General topological properties of switching structures, IEEE Power Electronics Specialists Conference, San Diego, CA, USA, 1979, pp. 109-130.

[7] D. Maksimovic and S. Cuk, Switching converters with wide DC conversion range, IEEE Transactions on Power Electronics, Vol. 6, No. 1, pp. 151-157, Jan. 1991.

[8] B. W. Williams, Generation and Analysis of Canonical Switching Cell DC-to-DC Converters, IEEE Transactions on Industrial Electronics, Vol. 61, No. 1, pp. 329-346, Jan. 2014.

[9] F. A. Himmelstoss, and K. H. Edelmoser, Modified Basic DC-DC Converters, Power Conversion and Intelligent Motion PCIM 2018, pp. 1076-1083.

[10] F. A. Himmelstoss and H. L. Votzi, A family of quadratic DC/DC converters with one low-side switch and a tapped inductor at the output side, 2019 International Aegean Conference on Electrical Machines and Power Electronics (ACEMP) \& 2019 International Conference on Optimization of Electrical and Electronic Equipment (OPTIM), Istanbul, Turkey, 2019, pp. 304-309.

[11] R. Marquez and M. A. Contreras-Ordaz, The ThreeTerminal Converter Cell, Graphs, and Generation of DCto-DC Converter Families, IEEE Transactions on Power Electronics, Vol. 35, No. 8, pp. 7725-7728, Aug. 2020.

[12] A. A. A. Ismail and A. Elnady, Advanced Drive System for DC Motor Using Multilevel DC/DC Buck Converter Circuit, IEEE Access, vol. 7, pp. 54167-54178, 2019.

[13] K. Vitols, N. Reinberg, A. Sokolovs and I. Galkin, Drive selection for electric kart, Proceedings of 14 th International Power Electronics and Motion Control Conference EPE-PEMC 2010, Ohrid, 2010.

[14] N. Bairachtaris, V. Petroulas, A. Safacas, E. Tatakis and S. Tsotoulidis, Design and construction of a four-channel interleaved buck dc/dc converter for an electric boat application, Electrical Systems for Aircraft, Railway and Ship Propulsion, Bologna, 2010, pp. 1-6.
[15] R. Silva-Ortigoza, V. M. Hernández-Guzmán, M. Antonio-Cruz and D. Muñoz-Carrillo, DC/DC Buck Power Converter as a Smooth Starter for a DC Motor Based on a Hierarchical Control, IEEE Transactions on Power Electronics, vol. 30, no. 2, pp. 1076-1084, 2015.

[16] M. Mahghani and E. Afjei, Carrier-based with unipolar switching technique current control of PMDC motors in electric vehicle applications, 2017 Iranian Conference on Electrical Engineering (ICEE), Tehran, 2017, pp. 10601065.

[17] L. Benaaouinate, M. Khafallah, A. Mesbahi and A. Martinez, Development of a useful wind turbine emulator based on permanent magnet DC motor, 2017 14th International Multi-Conference on Systems, Signals \& Devices (SSD), Marrakech, 2017.

[18] S. Pant and R. P. Saini, Solar Water Pumping System Modelling and Analysis using MATLAB/Simulink, 2020 IEEE Students Conference on Engineering \& Systems (SCES), Prayagraj, India,2020, pp. 1-6.

[19] S. Benzaouia, A. Rabhi, S. Zouggar and A. El Hajjaji, Design and Control of Standalone Wind Powered Water Pumping System, 2018 7th International Conference on Systems and Control (ICSC), Valencia, 2018, pp. 99-104.

[20] G. Shahgholian and P. Shafaghi, State space modeling and eigenvalue analysis of the permanent magnet DC motor drive system, 2010 2nd International Conference on Electronic Computer Technology, Kuala Lumpur, 2010, pp. 63-67.

[21] K. T. Chau and C. C. Chan, A SPICE compatible model of permanent magnet DC motor drives, Proceedings of 1995 International Conference on Power Electronics and Drive Systems PEDS 95, Singapore, 1995, pp. 477-482 vol.1.

\section{Creative Commons Attribution License 4.0 (Attribution 4.0 International, CC BY 4.0)}

This article is published under the terms of the Creative Commons Attribution License 4.0 https://creativecommons.org/licenses/by/4.0/deed.en_US

\section{APPENDIX}

Table A.I: Four-quadrant drive, modes for running to the right

\begin{tabular}{|l|c|c|c|c|c|c|c|c|c|c|c|c|}
\hline Mode & $\mathrm{S} 1$ & $\mathrm{D} 1$ & $\mathrm{~S} 2$ & $\mathrm{D} 2$ & $\mathrm{S3}$ & $\mathrm{D} 3$ & $\mathrm{~S} 4$ & $\mathrm{D} 4$ & $\mathrm{~S} 5$ & $\mathrm{D} 5$ & $\mathrm{S6}$ & $\mathrm{D} 6$ \\
\hline TM1 & $\mathrm{x}$ & & & & & & & & $\mathrm{x}$ & & $\mathrm{x}$ & \\
\hline TM2 & $\mathrm{x}$ & & $\mathrm{x}$ & & & & & & & & $\mathrm{x}$ & \\
\hline TM1 & $\mathrm{x}$ & & & & & & & & $\mathrm{x}$ & & $\mathrm{x}$ & \\
\hline FM2 & & & & & & $\mathrm{x}$ & & & & & $\mathrm{x}$ & \\
\hline FM1 & $\mathrm{x}$ & & & & & & & $\mathrm{x}$ & & & & \\
\hline FM2 & & & & & & $\mathrm{x}$ & & & & & $\mathrm{x}$ & \\
\hline RM1 & & & & $\mathrm{x}$ & & $\mathrm{x}$ & & $\mathrm{x}$ & & & & \\
\hline FM2 & & & & & & $\mathrm{x}$ & & & & & $\mathrm{x}$ & \\
\hline RM1 & & & & $\mathrm{x}$ & & $\mathrm{x}$ & & $\mathrm{x}$ & & & & \\
\hline RM2 & & & & & & $\mathrm{x}$ & & & & $\mathrm{x}$ & & $\mathrm{x}$ \\
\hline
\end{tabular}

Table A.II: Four-quadrant drive, modes for running to the left

\begin{tabular}{|l|c|c|c|c|c|c|c|c|c|c|c|c|}
\hline Mode & S1 & D1 & S2 & D2 & S3 & D3 & S4 & D4 & S5 & D5 & S6 & D6 \\
\hline TM1 & & & $\mathrm{x}$ & & $\mathrm{x}$ & & $\mathrm{x}$ & & $\mathrm{x}$ & & $\mathrm{x}$ & \\
\hline TM2 & & & & & $\mathrm{x}$ & & $\mathrm{x}$ & & $\mathrm{x}$ & & & \\
\hline TM1 & & & $\mathrm{x}$ & & $\mathrm{x}$ & & $\mathrm{x}$ & & & & $\mathrm{x}$ & \\
\hline FM2 & & & & & $\mathrm{x}$ & & & & & & & $\mathrm{x}$ \\
\hline FM1 & & $\mathrm{x}$ & & & & & $\mathrm{x}$ & & & & & \\
\hline FM2 & & & & & $\mathrm{x}$ & & & & & & & $\mathrm{x}$ \\
\hline RM1 & & $\mathrm{x}$ & & & & & & & & $\mathrm{x}$ & & $\mathrm{x}$ \\
\hline FM2 & & & & & $\mathrm{x}$ & & & & & & & $\mathrm{x}$ \\
\hline RM1 & & $\mathrm{x}$ & & & & $\mathrm{x}$ & & & & $\mathrm{x}$ & & $\mathrm{x}$ \\
\hline RM2 & & $\mathrm{x}$ & & $\mathrm{x}$ & & & & & & & & $\mathrm{x}$ \\
\hline
\end{tabular}

